\section{RMD Open}

Rheumatic \&

Musculoskeletal Diseases
To cite: Dejaco C, Putrik P, Unger J, et al. EULAR 'points to consider' for the conduction of workforce requirement studies in rheumatology. RMD Open 2018;4:e000780. doi:10.1136/ rmdopen-2018-000780

- Prepublication history for this paper is available online. To view these files, please visit the journal online (http://dx.doi. org/10.1136/rmdopen-2018000780).

$\mathrm{SR}$ and FB contributed equally.

Received 28 July 2018

Revised 30 August 2018

Accepted 22 September 2018

\section{SLinked}

- https://doi.org/10.1136/ rmdopen-2018-000756

Check for updates

(C) Author(s) (or their employer(s)) 2018. Re-use permitted under CC BY-NC. No commercial re-use. See rights and permissions. Published by BMJ.

For numbered affiliations see end of article.

Correspondence to Dr Christian Dejaco; christian.dejaco@gmx.net

\title{
EULAR 'points to consider' for the conduction of workforce requirement studies in rheumatology
}

Christian Dejaco, ${ }^{1,2}$ Polina Putrik, ${ }^{3}$ Julia Unger, ${ }^{4}$ Daniel Aletaha, ${ }^{5}$ Gerolamo Bianchi, ${ }^{6}$ Johannes W Bijlsma, ${ }^{7}$ Annelies Boonen, ${ }^{3}$ Nada Cikes, ${ }^{8}$ Axel Finckh, ${ }^{9}$ Laure Gossec, ${ }^{10,11}$ Tore K Kvien, $^{12}$ Joao Madruga Dias, ${ }^{13}$ Eric L Matteson, ${ }^{14}$ Francisca Sivera,${ }^{15}$ Tanja A Stamm, ${ }^{16}$ Zoltan Szekanecz, ${ }^{17}$ Dieter Wiek, ${ }^{18}$ Angela Zink, ${ }^{19,20}$ Sofia Ramiro, ${ }^{21,22}$ Frank Buttgereit ${ }^{20}$

\section{ABSTRACT}

Objective Current methods used for forecasting workforce requirements in rheumatology are disparate, as are the parameters incorporated into workforce projection studies. The objective of these European League Against Rheumatism (EULAR points to consider (PTC) is to guide future workforce studies in adult rheumatology in order to produce valid and reliable manpower estimates.

Methods The EULAR Standardised Operating Procedures were followed. A multidisciplinary task force with experts including patients with rheumatic diseases from 11 EULAR countries and the USA was assembled. A systematic literature review (SLR) was conducted to retrieve workforce models in rheumatology and other medical fields. PTC were based on expert opinion informed by the SLR, followed by group discussions with consensus obtained through informal voting. The level of agreement with the PTC was voted anonymously.

Results A total of 10 PTC were formulated. The task force recommends models integrating supply (=workforce available in rheumatology), demand (=health services requested by the population) and need (=health services that are considered appropriate to serve the population). In general, projections of workforce requirements should consider all factors relevant for current and future workload in rheumatology inside and outside of direct patient care. Forecasts of workforce supply should consider demography and attrition of rheumatologists, as well as the effects of new developments in healthcare. Predictions of future need/demand should take demographic, sociocultural and epidemiological development of the population into account.

Conclusion These EULAR-endorsed PTC will provide guidance on the methodology and the parameters to be applied in future national and international workforce requirement studies in rheumatology.

\section{INTRODUCTION}

The European League Against Rheumatism (EULAR) has been developing strategies and recommendations for early referral, diagnosis and management of patients with rheumatic

\section{Key messages}

What is already known about this subject?

- Calculation of manpower requirement in rheumatology is the basis for adequate service provision to the population in future.

- Current methods used for forecasting manpower are disparate resulting in projections that vary by a factor of five.

What does this study add?

- These are first European League Against Rheumatism (EULAR)-endorsed 'points to consider' (PTC) providing a framework for future workforce models in rheumatology. These PTC might also be applied by other medical disciplines.

- This article highlights areas of uncertainty and points to aspects that require further research.

How might this impact on clinical practice?

- It is anticipated that EULAR, national societies and healthcare planners will use these PTC as a basis for future workforce studies in rheumatology.

- The results of workforce studies should ultimately be translated into political actions assuring a sufficient number of rheumatologists to serve patients suffering from rheumatic and musculoskeletal diseases.

and musculoskeletal diseases (RMDs) in order to prevent disease-related damage from the early phase of the disease eventually causing functional restrictions, comorbidities and psychosocial isolation. ${ }^{1-5}$ In several countries, it is difficult to implement these recommendations because of limited manpower resources; rather, there are long waiting lists for a new patient rheumatology appointment. ${ }^{6}$ In addition, the demand for rheumatology services is expected to increase in the next years for several reasons: (1) the prevalence of RMDs is increasing due to increasing life expectancy in the general population, 
the introduction of new classification/diagnostic criteria capturing patients earlier in the disease and new treatment options improving patients' survival. ${ }^{7-9}$ (2) More healthcare resources are required for individual patients because of new therapies and novel tests for diagnosis and monitoring. ${ }^{10} 11$

Questions such as "how many rheumatologists are needed to meet current and future population needs?" have to be answered in order to adequately counsel future healthcare planners. Current methods used for forecasting manpower in rheumatology are disparate, as are the variables incorporated into projection models. ${ }^{12}$ The resulting projections from available studies vary by a factor of five (from 0.7/100 000 population in the UK to 3.5/100 000 in Spain), and appraisal of these studies is hampered by a lack of standardisation of methods for prediction. Hence, these publications do not provide a sound basis for healthcare policy recommendations and advice. $^{12}$

The broad objective of this project was to provide EULAR-endorsed 'points to consider' (PTC) for the methodology of future workforce requirement studies for rheumatologists. Studies based on these PTC should guide political actions in order to achieve a supply of rheumatologists sufficient to meet EULAR's goals of early diagnosis and treatment of patients with RMDs.

\section{METHODS}

After approval by the EULAR Executive Committee, the convenors $(\mathrm{CD}, \mathrm{FB})$ and the methodologist $(\mathrm{SR})$ led a task force guided by the 2014 updated EULAR Standardised Operating Procedures. ${ }^{13}$ The 20 task force members consisted of rheumatologists, epidemiologists, a methodologist, a health professional, and representatives from People with Arthritis/Rheumatism across Europe and EMerging EUlar NETwork from 11 EULAR countries and the USA. All members disclosed their conflicts of interest upfront. Two task force meetings took place. At the first meeting, the task force agreed on the following key questions: (1) "Is there a standardised approach/ best practice model in workforce requirement studies for rheumatologists and other medical fields concerning model selection, analysis, consideration of heterogeneity, stakeholder involvement, parameters included and data retrieval?"; (2) "What is the predictive value of identified workforce requirement studies?"

A systematic literature review (SLR) was conducted by two fellows (PP, JU) on workforce prediction studies in rheumatology and SLRs of studies from other medical fields. ${ }^{14}$ The evidence and quality assessment of retrieved studies was presented to the task force in the form of tables. A new tool for the appraisal of the quality of workforce studies was developed as part of this project. This tool and the SLR are published separately; ${ }^{14}$ however, they form an integral and inseparable part of the whole project together with the present PTC and should be read as such.
At the second meeting, the task force formulated the PTC based on evidence and expert opinion in a process of discussion and consensus, followed by final voting. Consensus was accepted if $\geq 75 \%(>67 \%,>50 \%)$ of the members voted in favour of the PTC at the first (second, third, respectively) round.

Finally, each task force member anonymously indicated the level of agreement via email (LoA; numeric rating scale ranging from $0=$ do not agree to $10=$ fully agree). The mean and SD of the LoA as well as the percentage of task force members with an agreement $\geq 8$ are presented.

Based on the gaps in evidence and the issues of controversy, a research agenda was formulated. The final manuscript was reviewed and approved by all task force members and approved by the EULAR Executive Committee.

\section{RESULTS}

These PTC are intended to guide future workforce requirement studies aiming to provide workforce targets for adult rheumatologists. We do not refer to models calculating the need/demand and supply of non-physician health professionals or other medical fields involved in the management of patients with RMDs. The targeted audiences are healthcare planners, epidemiologists, health professionals, politicians, rheumatologists, payers and patient organisations. Stakeholder involvement in workforce studies is essential; however, the perception of which stakeholders are relevant may vary between countries. The task force suggests including representatives from different geographical regions and involving at minimum rheumatologists, patient representatives, politicians and healthcare planners. Stakeholders have an advisory role in the selection of model and parameters, interpretation as well as consideration of scenarios for uncertainty analysis. They may serve as interviewees for qualitative (sub) studies when empirical data are absent. ${ }^{15}$

\section{Points to consider}

A total of 10 PTC have been formulated, which are summarised in table 1 and discussed in detail below.

PTC 1: Workforce models should integrate supply, demand and need of the respective geopolitical entity (eg, municipality, region, state, country), and should express results as full-time equivalents and as number of rheumatologists

'Supply' is the workforce available to rheumatology, 'demand' is defined as health services requested by the population and 'need' reflects the health services considered adequate to serve the population. ${ }^{16}{ }^{17}$ Need and demand are closely related; however, they do not necessarily overlap since there may be a higher or lower demand for services than what is deemed appropriate in the particular healthcare setting. Supply and demand interact, that is, new services may increase demand (supply-induced demand) and vice versa. ${ }^{15}$ The majority of workforce studies in rheumatology have 


\begin{tabular}{|c|c|c|c|}
\hline Number & Point to consider & LoA & LoE \\
\hline 1 & $\begin{array}{l}\text { Workforce models should integrate supply, demand and need of the respective geopolitical entity (eg, } \\
\text { municipality, region, state, country) and should express results as full-time equivalents and as number of } \\
\text { rheumatologists }\end{array}$ & $\begin{array}{l}9.5(0.9) \\
95 \% \geq 8\end{array}$ & 5 \\
\hline 2 & Workforce models should provide projections over a period of 5-15 years & $\begin{array}{l}9.1(1.1) \\
90 \% \geq 8\end{array}$ & 5 \\
\hline 4 & Workforce models should, where possible, rely on several data sources and include uncertainty analyses & $\begin{array}{l}9.8(0.4) \\
100 \% \geq 8\end{array}$ & 5 \\
\hline 5 & $\begin{array}{l}\text { Workforce models should be regularly updated; updates should include an analysis of the actual performance } \\
\text { (ie, prediction validity) of the previous model }\end{array}$ & $\begin{array}{l}9.5(0.6) \\
100 \% \geq 8\end{array}$ & 5 \\
\hline 6 & $\begin{array}{l}\text { Workforce need for patient care should be based on the prevalence and referral rates of diseases managed by } \\
\text { rheumatologists as well as on an estimation of time needed per patient }\end{array}$ & $\begin{array}{l}9.7(0.7) \\
100 \% \geq 8\end{array}$ & 5 \\
\hline 8 & $\begin{array}{l}\text { Workforce need and supply should consider work outside rheumatology patient care (eg, administrative tasks, } \\
\text { research, teaching, non-rheumatological disease management), as well as patient care performed by other } \\
\text { health professionals in rheumatology }\end{array}$ & $\begin{array}{l}9.4(0.9) \\
95 \% \geq 8\end{array}$ & 5 \\
\hline 9 & $\begin{array}{l}\text { Workforce supply should account for demographic composition of rheumatologists, the number of } \\
\text { rheumatologists entering and leaving the workforce, and generational attitudes of rheumatologists towards } \\
\text { scope of practice and work-life balance }\end{array}$ & $\begin{array}{l}9.1(2.3) \\
85 \% \geq 8\end{array}$ & 5 \\
\hline 10 & $\begin{array}{l}\text { Workforce models should consider the effects of medical developments, including new technologies, } \\
\text { medications, artificial intelligence and e-health, on demand and supply }\end{array}$ & $\begin{array}{l}9.4(1.1) \\
85 \% \geq 8\end{array}$ & 5 \\
\hline
\end{tabular}

Numbers in column 'LoA' indicate the mean and SD (in parentheses) of the LoA, as well as the percentage of task force members with an agreement $\geq 8$. None of the studies identified corresponded to any of the categories of Oxford Centre for Evidence-Based Medicine. ${ }^{64}$ Evidence level was therefore set as ' 5 ', which is the lowest level of evidence.

LoA, level of agreement; LoE, level of evidence

used integrated models and studied (at least in part) the factors influencing each of these factors. ${ }^{14}$

Effective workforce planning needs to consider regional heterogeneity of supply, demand and need, which may all vary across countries, states, regions and rural versus urban areas. ${ }^{17-19}$

Results of workforce requirement studies should be provided in full-time equivalents and head counts per reference population (eg, n/100 000 people) in order to take part-time work and time spent on non-clinical work into account, respectively.

\section{PTC 2: Workforce models should provide projections over a period of $5-15$ years}

An adequate period for prediction is pivotal in order to enable the translation of study results into political actions that will fill anticipated workforce gaps or reduce surplus if any exists.

Several workforce requirement studies in rheumatology provided only a baseline assessment (and are thus not true prediction studies), whereas others covered time frames between 5 and 25 years ${ }^{14}$ with some providing estimates for every 5 years. ${ }^{17} 2021$ The Handbook on Health Workforce Planning methodologies across EU countries suggests a period of 12-18 years for workforce studies in healthcare, and the Health Workforce Planning in OECD Countries proposes a time frame of 15-20 years. ${ }^{15} 16$ These reports consider the total length of medical training (medical school and specialisation) plus the time for implementation of political changes. The task force was of the opinion that for workforce studies in rheumatology, a shorter period would be more accurate because political actions will mostly occur at the level of specialisation, for example by regulating the number of training posts for rheumatologists. The average training time to become a rheumatologist after graduation from medical school varies between 3 and 8 years in Western countries. ${ }^{22}$

\section{PTC 3: Workforce models should not assume a current balance between supply and need}

The majority of workforce models in rheumatology assumed, mostly for simplicity, a balance between supply and need at baseline. ${ }^{14}$ This ignores the possibility of an oversupply or shortage of workforce relative to the actual need of the population, particularly in certain geographical areas, and may lead to further under or overestimation of future workforce requirements in rheumatology.

There are several possibilities to assess whether current supply meets demand, for example by analysing vacancies $(1 \%-3 \%$ is considered normal), waiting lists, locum lists, regional distribution and/or immigration trends of rheumatologists. ${ }^{152}$ Any current gap between healthcare use rates and need as recommended by clinical guidelines might also be an indicator of whether workforce supply meets population need (after correcting for other barriers of implementation such as lack of training or remuneration). ${ }^{16}$ Regrettably, the implementation of 
EULAR recommendations is still incomplete in several countries. ${ }^{24}$

\section{PTC 4: Workforce models should, where possible, rely on several} data sources and include uncertainty analyses

There was some discussion whether a PTC on data sources is required because prediction models should be based on solid evidence. Many factors included in workforce models are based on extrapolations and assumptions rather than on hard data because of the lack of studies. Therefore, the task force was of the opinion that prediction models should make use of several data sources. These constitute individual or aggregate data from observational studies including registries, but also surveys, expert consensus or other forms of qualitative research. ${ }^{1516}$ Examples where qualitative studies provide valuable information are questions like: "What proportion of patients with certain diseases should be managed by rheumatologists as opposed to other specialists?" or "What are the most important factors influencing supply and demand in a specific setting?" In contrast, parameters like disease prevalence or demographic changes of the population require an empirical basis. Given that data on these factors may be imprecise and heterogeneous, the confidence in estimates increases if data are gathered from several sources and reveal similar results.

The main goal of uncertainty analysis is to gain insight into which assumptions are most vulnerable and to understand the effect of modifying critical parameters on final estimates. It is generally expected that a workforce model results in better predictions if many parameters are considered ${ }^{25}$; however, a high number of assumptions might also limit the precision of the model. ${ }^{26} 27$

\section{PTC 5: Workforce models should be regularly updated; updates}

should include an analysis of the actual performance (ie, prediction validity) of the previous model

Although it seems implicit to update workforce models regularly, the task force decided to address this issue specifically. A regular update every 4 years at minimum is suggested, particularly if new data for the input variables become available. New clinical practice recommendations, new regulations affecting working time (such as overtime rules) or retirement age of physicians are examples of factors that may have a dramatic impact on workforce prediction. ${ }^{28} 29$ Authors of workforce models should regularly investigate whether observed changes correspond to expected ones. Weaknesses of the model, model assumptions and implementation should be addressed if the plan is off track. ${ }^{15}$

In rheumatology, updates and assessment of workforce models have only been performed and reported from Germany and the USA, although not within the 4-year time frame. ${ }^{20}{ }^{30}$ Both studies compared the overlap and divergence of estimates between the newer and the previous model. ${ }^{17} 18$ In the study of the U.S. Department of Health and Human Services, face validation by experts, a 'stress test' for extreme values, external and predictive validation against other data sources (not used for the model) as well as a validation of results against other models were performed. ${ }^{31}$

PTC 6: Workforce need for patient care should be based on the prevalence and referral rates of diseases managed by rheumatologists as well as on an estimation of time needed per patient

The task force unanimously agreed that the prevalence of diseases, the proportion of patients with a specific disease followed by rheumatologists as well as the time spent with an individual patient are the most important factors determining the workforce need in rheumatology. These factors, however, may be subject to large national and regional heterogeneity. In France, for example, rheumatologists follow many patients with degenerative RMDs, whereas in Germany, patients with these conditions are mainly referred to orthopaedic surgeons and other specialists. Given the high prevalence of degenerative RMDs, ${ }^{32}$ even small variations in the assumptions related to these conditions may have a large impact on the prediction of workforce need.

The task force decided to use the overarching term 'time needed per patient' that covers several aspects related to patient care. While some workforce models included a rough estimate of the annual time needed for individual patients (eg, 3 hours/year for a patient with vasculitis), ${ }^{33}$ others applied a more complex approach estimating the number and length of visits per patient/year considering the type of condition (eg, non-inflammatory vs inflammatory) and the disease phase (new-onset vs stable disease/ remission). ${ }^{18}{ }^{30}$ Other factors that should be considered are the type of visits (eg, onsite vs telephone/email consultations) as well as the time spent for technical procedures (eg, ultrasound) and interventions.

The task force recognised that it may be difficult to base estimates for these factors on empirical data; however, surveys as well as expert interviews might enable realistic assumptions.

\section{PTC 7: Workforce need for patient care should consider current and future demographics, sociocultural characteristics of the population and disease patterns}

The majority of workforce studies in rheumatology took ageing of the population into account. ${ }^{14}$ The task force recommends also considering other aspects of population demographics such as (changes of) socioeconomic status as well as migration patterns. Growth of minority groups from a certain genetic background for example might lead to an increase of the prevalence of formerly rare diseases, and immigrants from certain countries might need greater medical attention due to neglected rheumatological disease, comorbidities or (latent) infections that have become uncommon in the Western world. ${ }^{34-36}$ Ethnicity, social status and educational level have also an impact on disease outcomes and healthcare use across different diseases. ${ }^{37} 38$ The social view on health, the influence of the internet on health information and the 
help-seeking behaviour for rheumatic complaints might influence the expected demand of health services. ${ }^{39-41}$ Other demographic/social factors relevant to future healthcare need include obesity, smoking and nutrition trends, as these are risk factors for rheumatic diseases and their comorbidities. ${ }^{42-46}$

The expected evolution of diseases over time also needs to be considered. Factors such as longer life expectancy increase the need for medical services whereas better disease outcomes (eg, lower disability) may have the opposite effect. ${ }^{47}$

\section{PTC 8: Workforce need and supply should consider work outside} rheumatology patient care (eg, administrative tasks, research, teaching, non-rheumatologic disease management) as well as patient care performed by other health professionals in rheumatology

Rheumatologists work in patient care and also have tasks related to administration, teaching and research. In addition, they may perform clinical work outside rheumatology such as night shifts in departments of internal/ general medicine. The proportion of working time rheumatologists can spend on seeing patients with RMDs depends on the setting (eg, academic vs community hospital vs private practice) and on the national/regional regulations. In some countries such as Austria, rheumatologists frequently work within larger departments of internal medicine; hence, they have only a few hours a week for rheumatology outpatient clinics while working most of the time as general internists.

Another aspect that needs to be considered is the possibility of shifting clinical tasks from rheumatologists to general practitioners or other specialists (so called horizontal substitution), and/or to delegate work to other non-physician health professionals such as advanced nurse practitioners and physician assistants (vertical substitution). ${ }^{15}$ While the task force was reluctant to make any recommendation about which tasks could be delegated, an increasing task-shift can already be observed in several countries. ${ }^{48-51}$

Multidisciplinary team work such as co-joined outpatient clinics (eg, with dermatologists, gastroenterologists, paediatricians etc) or meetings with other specialists (radiologists, physiotherapists, specialised nurses etc) may also change the total workload for rheumatologists and other professionals, while they aim at improving the quality of care. ${ }^{52-54}$

\section{PTC 9: Workforce supply should account for demographic} composition of rheumatologists, the number of rheumatologists entering and leaving the workforce, and generational attitudes of rheumatologists towards scope of practice and work-life balance

Workforce models in rheumatology should consider expected retirement rates of rheumatologists, the lower number of visits performed by young rheumatologists due to lack of experience, as well as part-time work (common for older and female rheumatologists). Female physicians have been shown to perform fewer patient visits than male physicians (by $\sim 30 \%$ annually), ${ }^{55}$ and part-time workers usually have the same tasks in administration as full-time workers resulting in a lower availability for clinical care. A change of the perception of work (and work-life balance) can also be observed in newer as compared with older generations, which affects the willingness to work full-time and overtime. ${ }^{5657}$ While these aspects do not directly impact the quality of care (which should always be kept at a high level), workforce planners need to consider possible changes in the number of annual visits provided by individual rheumatologists.

The most important individual factors influencing the number of rheumatologists entering and leaving the market are training and retirement, respectively. Small variations in these parameters (eg, increment of retirement age) may have considerable effects on workforce supply. ${ }^{28} \mathrm{~A}$ solid projection of these parameters is therefore essential, as opposed to what has mostly been done. ${ }^{14}$ Other factors influencing workforce supply are migration and attrition. Attrition may be within the profession (ie, rheumatologists change to another specialty) or to another profession. Changes of working conditions such as altered salary or career prospects, modification of retirement age rules and workload affect the desirability of medical professions and thus supply, motivation and productivity of rheumatologists. ${ }^{58}$

\section{PTC 10: Workforce models should consider the effects} of medical developments, including new technologies, medications, artificial intelligence and e-health, on demand and supply

Ongoing medical developments such as availability of new medications, new or improved technical devices for diagnosis and monitoring as well as novel interventional procedures directly or indirectly influence the demand for workforce in rheumatology. New treatment options for example may improve the outcome of patients with RMDs thereby directly modifying the demand for medical services. ${ }^{47}$ Ultrasound and other diagnostic techniques, while informing medical decisions, increase the time needed for an individual patient visit. ${ }^{11}$ Technical developments alleviating clinical documentation may expand the time available to patients, and new qualification and training models of health professionals may lead to a higher task shift thus increasing the time resources of physicians to see more patients. ${ }^{59}$

The task force decided to mention e-health separately because of its importance for future healthcare and because it may be considered a 'medical' development only in part. Telemedicine, 'app'-based self-management or similar innovations may all reduce the need for faceto-face visits. ${ }^{60}$ At the same time, increasing 'self-diagnosis' of patients by such systems might also increase the demand for medical services. ${ }^{4161}$

Based on the discussions and the areas of uncertainty, a research agenda has been proposed, depicted in box 1 . 


\section{Box 1 Research agenda}

- Stimulate national and international rheumatology societies to run workforce prediction studies following these points to consider.

- Evaluate and compare the quality of workforce studies performed before and after these EULAR points to consider.

- Conduct workforce studies integrating workforce calculation for rheumatologists, other medical fields and other non-physician health professionals.

Determine the optimal number of factors to be included in workforce calculation models.

- Identify the most influential factors to be included in workforce calculation models, and quantify the relative importance of various items (weighting) included in workforce models.

- Determine the optimal number and type of data sources.

- Develop methods for the validation of workforce models.

- Determine the best statistical approach for model calculation and uncertainty analysis.

\section{DISCUSSION}

These are the first EULAR-endorsed PTC providing a framework for future workforce models in rheumatology, which may eventually be applied by other medical disciplines. The task force recognised that health workforce planning is not an exact quantification science; rather, it is an iterative process in which the ability to measure and predict improves over time. ${ }^{16}$ Translation of workforce models into political actions, regular monitoring of whether observed changes correspond to predictions, as well as ongoing adaption of parameters to reality are essential to obtain a practical and useful model ('plando-check-adjust') ${ }^{62}$

Several recommendations were based on expert opinion because evidence was limited or absent for many aspects. ${ }^{14}$ This has been acknowledged both in the PTC and in the research agenda, which should stimulate further research to fill the gaps of knowledge in the field.

The present PTC are intended to be applied in future models predicting the requirements for rheumatologist manpower. Complex studies calculating the number of all medical professionals required for the care of patients with RMDs (including general practitioners, other specialists and health professionals) are not within the scope of this work. Given the dynamic development of task shifting from one to another profession, models focused on rheumatologists assume a sufficient supply of other health professionals, which does not always correspond to reality. ${ }^{1763}$ On the other hand, complex studies might lose precision because several estimations and extrapolations are necessary to generate the model.

The task force discussed and acknowledged the importance of economic development and health budget on supply and demand/need but did not achieve a consensus to formulate a specific proposition. ${ }^{15}$ The health budget may determine the investments in regional health services, the opening of new health centres (which might mainly influence demand) and replacement of health professionals that have retired. In case of a shortage of specialists (and assuming budget is available), higher expenditures for specialised training, improved working conditions and wages are potential political levers to increase the influx of professionals.

It is anticipated that EULAR, national societies and healthcare planners will use these PTC as a basis for future workforce studies in rheumatology. These should ultimately be translated into political actions to assure a sufficient number of rheumatologists at EU, national and regional levels to adequately serve patients suffering from RMDs.

\section{Author affiliations}

${ }^{1}$ Department of Rheumatology and Immunology, Medical University Graz, Graz, Austria

${ }^{2}$ Department of Rheumatology, Hospital of Bruneck, Bruneck, Italy

${ }^{3}$ Department of Internal Medicine, Division of Rheumatology, Maastricht University Medical Center and Care and Public Health Research Institute, Maastricht University, Maastricht, The Netherlands

${ }^{4}$ Department of Health Studies, FH JOANNEUM, University of Applied Sciences, Bad Gleichenberg, Austria

${ }^{5}$ Division of Rheumatology, Medical University Vienna, Vienna, Austria

${ }^{6}$ Division of Rheumatology, ASL3-Azienda Sanitaria Genovese, Genova, Italy ${ }^{7}$ Department of Rheumatology \& Clinical Immunology, University Medical Center Utrecht, Utrecht, The Netherlands

${ }^{8}$ Division of Clinical Immunology \& Rheumatology, School of Medicine, University of Zagreb, Zagreb, Croatia

${ }^{9}$ Division of Rheumatology, Department of Internal Medicine Specialities, Geneva University Hospital, Geneva, Switzerland

${ }^{10}$ Rheumatology Department, Pitié Salpêtrière hospital, APHP, Paris, France

${ }^{11}$ Sorbonne Université, Paris, France

${ }^{12}$ Department of Rheumatology, Diakonhjemmet Hospital, Oslo, Norway

${ }^{13}$ Department of Rheumatology, Centro Hospitalar Médio Tejo, Torres Novas, Portugal

${ }^{14}$ Division of Rheumatology and Department of Health Sciences Research, Mayo Clinic College of Medicine, Rochester, United States

${ }^{15}$ Department of Rheumatology, Hospital General Universitario de Elda, Elda, Spain

${ }^{16}$ Section for Outcomes Research, Center for Medical Statistics, Informatics, and Intelligent Systems, Medical University of Vienna, Vienna, Austria

${ }^{17}$ Faculty of Medicine, Department of Internal Medicine, Division of Rheumatology, University of Debrecen, Debrecen, Hungary

${ }^{18}$ EULAR Standing Committee of PARE, Zurich, Switzerland

${ }^{19}$ Deutsches Rheuma-Forschungszentrum, Berlin, Germany

${ }^{20}$ Department of Rheumatology and Clinical Immunology, Charitè University Hospital, Berlin, Germany

${ }^{21}$ Department of Rheumatology, Leiden University Medical Centre, Leiden, The Netherlands

${ }^{22}$ Zuyderland Medical Center, Heerlen, The Netherlands

Acknowledgements The authors would like to thank Louise Falzon for her work in the development of the literature search strategy and Federico Torres for his support in the communication with Public Affairs section of EULAR.

Contributors All authors were involved in the discussion and formulation of the points to consider. CD wrote the first version of the manuscript. All authors reviewed it and made extensive comments and appropriate changes to it. All authors approved the final version of the manuscript.

Funding Funding was provided by the European League Against Rheumatism. Competing interests None declared.

Patient consent Not required.

Provenance and peer review Not commissioned; externally peer reviewed. Data sharing statement № additional data are available.

Open access This is an open access article distributed in accordance with the Creative Commons Attribution Non Commercial (CC BY-NC 4.0) license, which permits others to distribute, remix, adapt, build upon this work non-commercially, and license their derivative works on different terms, provided the original work is 
properly cited, appropriate credit is given, any changes made indicated, and the use is non-commercial. See: http://creativecommons.org/licenses/by-nc/4.0/.

\section{REFERENCES}

1. Emery P, Breedveld FC, Dougados M, et al. Early referral recommendation for newly diagnosed rheumatoid arthritis: evidence based development of a clinical guide. Ann Rheum Dis 2002;61:290-7.

2. Smolen JS, Landewé R, Bijlsma J, et al. EULAR recommendations for the management of rheumatoid arthritis with synthetic and biological disease-modifying antirheumatic drugs: 2016 update. Ann Rheum Dis 2017;76:960-77.

3. Combe B, Landewe R, Daien Cl. 2016 update of the EULAR recommendations for the management of early arthritis. Ann Rheum Dis 2016;2017:948-59.

4. Gossec L, Smolen JS, Ramiro S, et al. European League Against Rheumatism (EULAR) recommendations for the management of psoriatic arthritis with pharmacological therapies: 2015 update. Ann Rheum Dis 2016;75:499-510.

5. van der Heijde D, Ramiro S, Landewé R, et al. 2016 update of the ASAS-EULAR management recommendations for axial spondyloarthritis. Ann Rheum Dis 2017;76:978-91.

6. Delaurier A, Bernatsky S, Baron M, et al. Wait times for rheumatology consultation: is rheumatoid arthritis prioritized? $\mathrm{J}$ Clin Rheumatol 2012;18:341-4.

7. Smith E, Hoy DG, Cross M, et al. The global burden of other musculoskeletal disorders: estimates from the Global Burden of Disease 2010 study. Ann Rheum Dis 2014;73:1462-9.

8. van der Linden MP, Knevel R, Huizinga TW, et al. Classification of rheumatoid arthritis: comparison of the 1987 American College of Rheumatology criteria and the 2010 American College of Rheumatology/European League Against Rheumatism criteria. Arthritis Rheum 2011;63:37-42.

9. Yen EY, Shaheen M, Woo JMP. 46-year trends in systemic lupus erythematosus mortality in the United States, 1968 to 2013: a nationwide population-based study. Ann Intern Med 2017;167:777.

10. Smolen JS, Breedveld FC, Burmester GR, et al. Treating rheumatoid arthritis to target: 2014 update of the recommendations of an international task force. Ann Rheum Dis 2016;75:3-15.

11. Schirmer M, Duftner C, Schmidt WA, et al. Ultrasonography in inflammatory rheumatic disease: an overview. Nat Rev Rheumatol 2011;7:479-88.

12. Dejaco C, Lackner A, Buttgereit F, et al. Rheumatology workforce planning in Western Countries: a systematic literature review. Arthritis Care Res 2016;68:1874-82.

13. van der Heijde D, Aletaha D, Carmona L, et al. 2014 Update of the EULAR standardised operating procedures for EULAR-endorsed recommendations. Ann Rheum Dis 2015;74:8-13.

14. Unger J, Putrik P, Buttgereit F, et al. Workforce requirements in rheumatology: a systematic literature review informing the development of a workforce prediction risk of bias tool and the EULAR points to consider. RMD Open 2018.

15. Malgieri A, Michelutti P, Van Hoegaerden M. Handbook on health workforce planning methodologies across EU countries, 2015.

16. Ono T, Lafortune G, Schoenstein M. Health workforce planning in OECD countries: a review of 26 projection models from 18 countries. OECD Heal Work Pap 2013;62.

17. Battafarano DF, Ditmyer M, Bolster MB. American College of Rheumatology workforce study: supply and demand projections of adult rheumatology workforce (2015-2030). Arthritis Care Res 2015;2018:617-26.

18. Zink A, Braun J, Gromnica-Ihle E, et al. [Memorandum of the German Society for Rheumatology on the quality of treatment in rheumatology-Update 2016]. Z Rheumatol 2017;76:195-207.

19. US Department of Health and Human Services, 2015. Technical documentation for health resources and services administration's health workforce simulation model. Available from: https://bhw.hrsa. gov/sites/default/files/bhw/nchwa/projections/simulationmodeld ocumentation.pdf

20. Deal CL, Hooker R, Harrington $\mathrm{T}$, et al. The United States rheumatology workforce: supply and demand, 2005-2025. Arthritis Rheum 2007;56:722-9.

21. Hanly JG, Canadian Council of Academic Rheumatologists. Manpower in Canadian academic rheumatology units: current status and future trends. Canadian Council of Academic Rheumatologists. J Rheumatol 2001;28:1944-51.

22. Sivera F, Ramiro S, Cikes N, et al. Differences and similarities in rheumatology specialty training programmes across European countries. Ann Rheum Dis 2015;74:1183-7.
23. Zurn P, Dal Poz MR, Stilwell B, et al. Imbalance in the health workforce. Hum Resour Health 2004;2:13.

24. Gvozdenović E, Allaart CF, van der Heijde D, et al. When rheumatologists report that they agree with a guideline, does this mean that they practise the guideline in clinical practice? Results of the International Recommendation Implementation Study (IRIS). RMD Open 2016;2:e000221.

25. Rafiei S, Mohebbifar R, Hashemi F, et al. Approaches in health human resource forecasting: a roadmap for improvement. Electron Physician 2016;8:2911-7.

26. Feil EC, Welch HG, Fisher ES. Why estimates of physician supply and requirements disagree. JAMA 1993;269:2659-63.

27. Tomblin Murphy G, Birch S, MacKenzie A, et al. Simulating future supply of and requirements for human resources for health in highincome OECD countries. Hum Resour Health 2016;14:77.

28. Attal-Toubert K, Vanderschelden M. La démographie médicale I'horizon 2030: de nouvelles projections nationales et régionales détaillées. Dossiers Solidarité Santé, No.12. Paris: DREES, 2009.

29. The Europan Parliament and the council of the European Union, 2003. Directive 2003/88/EC of the European Parliament and of the Council of 4 November 2003 concerning certain aspects of the organisation of working time. Available from: http://eur-lex.europa. eu/legal-content/EN/TXT/HTML/?uri=CELEX:32003L0088\&from= $\mathrm{DE}$

30. Versorgung K, 2008. Anhaltszahlen zum Bedarf an internistischen Rheumatologen, Kinderrheumatologen, Akut-krankenhausbetten und medizinischer Rehabilitation. Available from: http://dgrh.de/ anhaltszahlen00.html

31. U.S. Department of Health and Human Services Health Resources and Services Administration National Center for Health Workforce Analysis, 2016. National and Regional Projections of Supply and Demand for Internal Medicine Subspecialty Practitioners. Available from: https://bhw.hrsa.gov/sites/default/files/bhw/health-workforceanalysis/research/projections/internal-medicine-subspecialty-report. pdf

32. Lawrence RC, Felson DT, Helmick CG, et al. Estimates of the prevalence of arthritis and other rheumatic conditions in the United States. Part II. Arthritis Rheum 2008:58:26-35.

33. Edworthy S. Canadian rheumatologists: an endangered species. Can Med Assoc J 2000;10:6-10.

34. Mahr A, Belarbi L, Wechsler B, et al. Population-based prevalence study of Behçet's disease: differences by ethnic origin and low variation by age at immigration. Arthritis Rheum 2008;58:3951-9.

35. Bartalesi $F$, Scirè $C$, Requena-Méndez $A$, et al. Recommendations for infectious disease screening in migrants to Western Europe with inflammatory arthropathies before starting biologic agents. Results from a multidisciplinary task force of four European societies (SIR, SER, SIMET, SEMTSI) facing the largest impact of the flow of migrants today. Clin Exp Rheumatol 2017;35:752-65.

36. Escalante P, Kooda KJ, Khan R, et al. Diagnosis of latent tuberculosis infection with T-SPOT(囚).TB in a predominantly immigrant population with rheumatologic disorders. Lung 2015;193:3-11.

37. Jacobi CE, Mol GD, Boshuizen HC, et al. Impact of socioeconomic status on the course of rheumatoid arthritis and on related use of health care services. Arthritis Rheum 2003;49:567-73.

38. Sutcliffe N, Clarke AE, Gordon C, et al. The association of socioeconomic status, race, psychosocial factors and outcome in patients with systemic lupus erythematosus. Rheumatology 1999;38:1130-7.

39. van Nies JA, Brouwer E, de Rooy DP, et al. Reasons for medical help-seeking behaviour of patients with recent-onset arthralgia. Ann Rheum Dis 2013;72:1302-7.

40. Powley L, Mcllroy G, Simons G, et al. Are online symptoms checkers useful for patients with inflammatory arthritis? BMC Musculoskelet Disord 2016;17:362.

41. White RW, Horvitz E. Web to world: predicting transitions from selfdiagnosis to the pursuit of local medical assistance in web search. AMIA Annu Symp Proc 2010;2010:882-6.

42. Woolf AD, Breedveld F, Kvien TK. Controlling the obesity epidemic is important for maintaining musculoskeletal health. Ann Rheum Dis 2006;65:1401-2.

43. Stolt P, Bengtsson C, Nordmark B, et al. Quantification of the influence of cigarette smoking on rheumatoid arthritis: results from a population based case-control study, using incident cases. Ann Rheum Dis 2003;62:835-41.

44. Di Giuseppe D, Wallin A, Bottai M, et al. Long-term intake of dietary long-chain n-3 polyunsaturated fatty acids and risk of rheumatoid arthritis: a prospective cohort study of women. Ann Rheum Dis 2014;73:1949-53.

45. Macfarlane GJ, de Silva V, Jones GT. The relationship between body mass index across the life course and knee pain in 
adulthood: results from the 1958 birth cohort study. Rheumatology 2011;50:2251-6.

46. Barbhaiya M, Tedeschi SK, Lu B, et al. Cigarette smoking and the risk of systemic lupus erythematosus, overall and by anti-double stranded DNA antibody subtype, in the Nurses' Health Study cohorts. Ann Rheum Dis 2018;77:196-202.

47. Smolen JS, Aletaha D, Barton A, et al. Rheumatoid arthritis. Nat Rev Dis Primers 2018;4:18001.

48. Solomon DH, Bitton A, Fraenkel L, et al. Roles of nurse practitioners and physician assistants in rheumatology practices in the US. Arthritis Care Res 2014;66:1108-13.

49. Goh L, Samanta J, Samanta A. Rheumatology nurse practitioners' perceptions of their role. Musculoskeletal Care 2006;4:88-100.

50. van Eijk-Hustings $Y$, Ndosi M, Buss B, et al. Dissemination and evaluation of the European League Against Rheumatism recommendations for the role of the nurse in the management of chronic inflammatory arthritis: results of a multinational survey among nurses, rheumatologists and patients. Rheumatology 2014;53:1491-6.

51. van Eijk-Hustings $Y$, van Tubergen $A$, Boström $C$, et al. EULAR recommendations for the role of the nurse in the management of chronic inflammatory arthritis. Ann Rheum Dis 2012;71:13-19.

52. Ndosi M, Ferguson R, Backhouse MR, et al. National variation in the composition of rheumatology multidisciplinary teams: a crosssectional study. Rheumatol Int 2017;37:1453-9.

53. Gratacos-Masmitja J, Luelmo-Aguilar J, Zarco-Montejo P, et al. Points to consider in the foundation of multidisciplinary units for psoriatic arthritis: a Delphi study and a systematic review of the literature. Adv Ther 2017;33:2150-9.

54. Magro-Checa C, Zirkzee EJ, Beaart-van de Voorde LJJ, et al. Value of multidisciplinary reassessment in attribution of neuropsychiatric events to systemic lupus erythematosus: prospective data from the Leiden NPSLE cohort. Rheumatology 2017;56:1676-83.

55. Association of American Medical Colleges (AAMC), 2016. The complexities of physician supply and demand projections from 2014 to 2025; 2016 update,Final Report April 2016. Available from: https:// www.aamc.org/download/458082/data/2016_complexities_of_ supply_and_demand_projections.pdf

56. Buddeberg-Fischer B, Stamm M, Buddeberg C, et al. The new generation of family physicians - career motivation, life goals and work-life balance. Swiss Med Wkly 2008;138:305-12.

57. Johannessen KA, Hagen TP. Individual and hospital-specific factors influencing medical graduates' time to medical specialization. Soc Sci Med 2013;97:170-5.

58. Buchan J, Wismar M, Glinos I. Health professional mobility in a changing Europe. New dynamics, mobile individuals and diverse responses. Copenhagen, 2014

59. Vliet Vlieland TP, van den Ende $\mathrm{CH}$, Alliot-Launois $\mathrm{F}$, et al. Educational needs of health professionals working in rheumatology in Europe. RMD Open 2016;2:e000337.

60. Piga M, Cangemi I, Mathieu A, et al. Telemedicine for patients with rheumatic diseases: systematic review and proposal for research agenda. Semin Arthritis Rheum 2017;47:121-8.

61. Ryan A, Wilson S. Internet healthcare: do self-diagnosis sites do more harm than good? Expert Opin Drug Saf 2008;7:227-9.

62. Shewhart W. Statistical method from the viewpoint of quality control. New York: Dover Publications, 1986.

63. Chan ZC, Tam WS, Lung MK, et al. A systematic literature review of nurse shortage and the intention to leave. J Nurs Manag 2013;21:605-13.

64. OCEBM Levels of Evidence Working Group, 2011. The Oxford 2011 levels of evidence. Available from: http://www.cebm.net/index.aspx? $\mathrm{o}=5653$ 